\title{
Subsidies in oligopoly markets: a welfare comparison between symmetric and asymmetric costs
}

Stephen F. Hamilton and Rickard Sandin

Oligopolistic industries generally produce less than is socially desirable. As a result, the use of production subsidies is often suggested as a means of raising production toward the efficient level in imperfectly competitive markets. In cases where firms are equally efficient in producing the good, the common prescription is a policy of uniform subsidization, as suggested by Besley (1989).(1) When firms in an industry differ in cost efficiency, however, uniform subsidization involves subsidizing inefficient firms in the same manner as efficient firms. Consequently, uniform policy may be undesirable from a social perspective, particularly when the price-cost margins of inefficient firms are small.

In an oligopolistic industry comprising firms that differ in cost effectiveness, one might ideally like to subsidize only the most efficient firm(s) and perhaps tax or even exclude inefficient firms from the market. Yet, in many situations, treating rival firms in an industry differently is politically infeasible. It is therefore important to understand how the welfare implications of uniform policy in an asymmetric-cost industry diverge from the case of equal cost efficiency. Different welfare implications are likely to arise because changes in regulatory structure can affect market structure in an asymmetric-cost industry (see Dierickx, Matutes, and Neven 1988; Kimmel 1992).

Several papers in the public finance literature have addressed the issue of tax incidence on the rivalry and profitability of firms in oligopoly markets. Katz and Rosen (1985) show, in a 
conjectural variations model with symmetric firms, that a uniform tax on production can lead to an outcome with larger after-tax profits for firms. This result is also supported by Dierickx, Matutes, and Neven (1988); Kimmel (1992); and Seade (1985) for the case when the cost efficiency of firms differs. However, these papers do not directly analyze the industry profit and social welfare effects of a change in the tax or subsidy program.

This article identifies relevant implications for tax policy by comparing welfare changes in the asymmetric-cost case to a benchmark case of symmetric costs. It is shown that, relative to the symmetric-cost case, the welfare effect is smaller when demand is nonconvex in the asymmetriccost case, while the opposite is true for the case of convex demand. The greater the cost asymmetry in the industry and the more collusive firm behavior, the greater is this difference in welfare impact.

\section{THE MODEL}

Consider a traditional conjectural variation model with two firms producing a homogeneous good.(2) We assume full information and profit-maximizing behavior for both firms. Letting 1 and $\mathrm{h}$ denote the low- and high-cost firm, respectively, the profit expression for firm $\mathrm{i}$ is

[Mathematical Expression Omitted] (1)

where $\mathrm{P}(\mathrm{Q})$ is the inverse demand function, $\mathrm{Q}=\mathrm{q}_{1}+\mathrm{q}_{\mathrm{h}}, \mathrm{c}_{\mathrm{i}}\left(\mathrm{q}_{\mathrm{i}}\right)$ is the cost function of firm $\mathrm{i}$, and $\mathrm{t}$ is a unit production subsidy $(\mathrm{t}>0)$. (3) The cost function is quadratic and has the form

$c_{i}\left(q_{i}\right)=\alpha_{i} q_{i}+\theta / 2\left(q_{i}\right)^{2}, i=1, h(2)$ 
where the parameter $\theta$ is identical for both types of firm, which means the difference in cost efficiency between firms is characterized entirely by a level effect. The relative efficiency of low- and high-cost firms is thus described by $\alpha_{\mathrm{h}}>\alpha_{1}$ in expression (2).

Differentiating expression (1) for firm i yields the first-order condition:

$\mathrm{P}(\mathrm{Q})+(1+\Delta) \mathrm{q}_{\mathrm{i}} \mathrm{P}^{\prime}(\mathrm{Q})-\mathrm{c}_{\mathrm{i}}^{\prime}\left(\mathrm{q}_{\mathrm{i}}\right)+\mathrm{t}=0, \mathrm{i}=1, \mathrm{~h}(3)$

and the second-order condition,

$2(1+\Delta) \mathrm{P}^{\prime}(\mathrm{Q})+(1+\Delta){ }_{2 \mathrm{qi}} \mathrm{P}^{\prime \prime}(\mathrm{Q})-\theta<0, \mathrm{i}=1, \mathrm{~h}(4)$

where $\Delta$ denotes the firm's conjectural variation parameter.(4) For stability, we assume that the marginal cost curve of each firm does not fall faster than residual demand,(5)

$\theta>(1+\Delta) \mathrm{P}^{\prime}(\mathrm{Q}) \cdot(5)$

Expression (5) limits the allowable degree of concavity of the cost functions.(6)

In the following analysis, we compare welfare implications of the asymmetric-cost industry to that of a symmetric-cost industry. To establish a benchmark, we assume for comparative purposes that the sum of intercept values of the marginal cost function is equal between the symmetric- and the asymmetric-cost case; that is,

$\alpha_{1}+\alpha_{\mathrm{h}}=2 \alpha_{\mathrm{s}},(6)$

where s denotes the symmetric firm. Equation (6) calibrates firms in the symmetric-cost case with the average level of cost efficiency in the asymmetric-cost case, which allows us to 
reference a meaningful benchmark. What we bring about by (6) are parallel shifts of the marginal cost curves of the high- and low-cost firm from the symmetric-cost case (upwards and downwards, respectively) that hold total industry output constant.

\section{EFFECTS OF A PRODUCTION SUBSIDY}

A production subsidy placed in an oligopoly industry affects welfare for both consumers and producers. We first focus on the producer effects because changing production incentives affect industry output, which in turn alters consumer surplus. A change in the subsidy rate affects total industry profit as

$\mathrm{d} \pi / \mathrm{dt}=\mathrm{d} \pi_{1} / \mathrm{dt}+\mathrm{d} \pi_{\mathrm{h}} / \mathrm{dt}=\mathrm{PdQ} / \mathrm{dt}+\mathrm{QdP} / \mathrm{dt}-\alpha_{1}+\theta_{\mathrm{ql}} \mathrm{dq} / \mathrm{dt}-\alpha_{\mathrm{h}}+\theta_{\mathrm{qh}} \mathrm{dq} / \mathrm{dt}+\mathrm{tdQ} / \mathrm{dt}+\mathrm{Q}$. (7)

We next derive an expression for $\mathrm{dq} / \mathrm{dt}$ by totally differentiating expression (3) for each firm. Writing these equations in matrix form,

[Mathematical Expression Omitted], (8)

and applying Cramer's rule, the movement of individual firm output in response to the subsidy is

$\mathrm{dq}_{1} / \mathrm{dt}=\theta-(1+\Delta) \mathrm{P}^{\prime}+(1+\Delta)^{2}\left(\mathrm{q}_{1}-\mathrm{q}_{\mathrm{h}}\right) \mathrm{P}^{\prime \prime} / \mathrm{D}(9)$

and

$\mathrm{d}_{\mathrm{qh}} / \mathrm{d}_{\mathrm{t}}=\theta-(1+\Delta) \mathrm{P}^{\prime}+(1+\Delta)^{2}\left(\mathrm{q}_{\mathrm{h}}-\mathrm{q}_{1}\right) \mathrm{P}^{\prime \prime} / \mathrm{D},(10)$

respectively, where $\mathrm{D}>0$ is the determinant of the coefficient matrix in (8). Because we are interested in comparing the difference in total welfare effects of a subsidy between the 
symmetric- and asymmetric-cost case, our primary concern is the change in industry quantity, which is obtained by summing equations (9) and (10) to get

$\mathrm{dQ} / \mathrm{dt}=2\left(\theta-(1+\Delta) \mathrm{P}^{\prime}\right) / \mathrm{D},(11)$

where the inequality holds by stability condition (5). This result is consistent with Seade (1985) and Besley (1989), who compute a negative sign for a unit tax on production in a homogeneous firm oligopoly.

Substituting equations (9), (10), and (11) into (7), we can calculate the change in profit following a subsidy in the asymmetric-cost industry. Because our goal is to contrast the effect of a subsidy between the symmetric- and asymmetric-cost case, however, the analysis can be simplified by recognizing that many of the terms in equation (7) are identical. The properties of the quadratic cost function above, in fact, ensure that the movement in industry quantity is independent of cost structure. This result can-be seen by summing the first-order conditions of low- and high-cost firms to obtain

$2 \mathrm{P}+(1+\Delta) \mathrm{QP}^{\prime}-\theta \mathrm{Q}=2\left(\left[\alpha_{\mathrm{s}}\right]-\mathrm{t}\right),(12)$

where the substitution $\alpha_{1}+\alpha_{h}=2 \alpha_{s}$ has been made using (6). Noting that equation (12) is expressed strictly in terms of the marginal cost of a symmetric- cost firm, it follows that the movement in total industry quantity is independent of the industry cost structure.(7) Thus, the change in aggregate quantity in response to a unit subsidy is the same, the arguments of $\mathrm{P}, \mathrm{P}^{\prime}$, and $\mathrm{P}$ " coincide between the symmetric- and asymmetric-cost case, and the change in consumer surplus is independent of industry cost structure. An identical change in industry quantity also implies that the total subsidy cost to the regulator is the same, whence the welfare comparison 
between the symmetric- and asymmetric-cost case reduces to the effect of subsidization on industry profitability. It is now relatively straightforward to compare the welfare effects of a unit subsidy in the asymmetric-cost case to those in the benchmark case of symmetric-cost firms.

\section{THE WELFARE COMPARISON}

Subtracting the change in industry profit in the symmetric-cost case from that in the asymmetriccost case results in the following expression:

$\psi=\mathrm{d} \pi^{\mathrm{A}} / \mathrm{dt}-\mathrm{d} \pi^{\mathrm{s}} / \mathrm{dt}=2 \alpha_{\mathrm{s}}+\theta_{\mathrm{qs}} \mathrm{d}[\mathrm{q} . \mathrm{sub}.] / \mathrm{dt}-\alpha_{1}+\theta_{\mathrm{ql}} \mathrm{dq} \mathrm{dt}^{\mathrm{dt}}-\alpha_{\mathrm{h}}+\theta_{\mathrm{gh}} \mathrm{dq} / \mathrm{dt},(13)$

where the superscripts $\mathrm{A}$ and $\mathrm{S}$ denote industry profit in the asymmetric-and symmetric-cost case, respectively. The comparative statics effect can be calculated from expression (9), recognizing that $\mathrm{q}_{1}=\mathrm{q}_{\mathrm{h}}$ for the symmetric-cost case. Substituting equations (9), (10), and the expression for $\mathrm{d}_{\mathrm{qs}} / \mathrm{dt}$ into equation (13) and making use of (6) yields, after some manipulation,

$\psi=1 / \mathrm{D}(1+\Delta)^{2}\left(\mathrm{q}_{1}-\mathrm{q}_{\mathrm{h}}\right) \mathrm{c}_{\mathrm{h}}^{\prime}-\mathrm{c}^{\prime \prime} \mathrm{P}^{\prime \prime},(14)$

where $\mathrm{c}_{\mathrm{i}}^{\prime}=\alpha_{\mathrm{i}}+\theta_{\mathrm{qi}}$. Our main results follow directly from expression (14), recognizing that all terms except $\mathrm{P}$ " are unambiguously positive.

\section{PROPOSITION}

(i) The welfare effect is smaller (larger) in the asymmetric case when demand is concave (convex). The greater the degree of concavity (convexity), the smaller (larger) the welfare effect in the asymmetric case. 
(ii) The greater the degree of collusion in the industry, the greater the magnitude of the difference in the welfare effect.

(iii) The greater the cost difference is between the firms in the asymmetric case, the greater the magnitude of the difference in the welfare effect.

The intuition behind (i) is that when the demand function is concave, the high-cost firm is on a more elastic portion of the marginal revenue curve than the low-cost firm and thus adjusts its quantity by more to restore the first-order condition. It thereby contributes to a greater than proportional share of the increase in total industry output.(8) The reverse is true if demand is convex. With linear demand, the difference in welfare change from the production subsidy is identical between the two cases, but because initial welfare is greater in the asymmetric case (due to the low-cost firm producing more than the high-cost firm), the percentage change is smaller in the asymmetric case. Uniform production subsidies distort market shares in favor of the highcost firm when demand is nonconvex, thus giving a smaller welfare effect in the asymmetric case.(9)

\section{CONCLUDING REMARKS}

This article has demonstrated the importance of industry cost structure in determining the welfare implications of uniform policy in imperfectly competitive markets. When firms differ in cost efficiency, the change in welfare from a subsidy is not necessarily the same as in the case of symmetric-cost firms. Demand conditions have been shown to determine the sign and influence the magnitude of the welfare difference, whereas cost conditions and the degree of industry 
collusion only influence the magnitude. Uniform tax policy can thus lead to a greater or lesser welfare change than expected when potential cost asymmetry is ignored in policy analysis.

Using the results in this article, it is possible to draw inferences on market demand convexity by observing changes in market share that occur following the imposition of uniform taxes and subsidies? An implication of the model is that the market share of the low-cost firm increases in response to an increase in the subsidy rate when demand is convex, yet decreases when demand is concave. This result allows for future empirical research to parameterize demand convexity in oligopolistic industries.

When a subsidy is placed in an industry with asymmetric costs, the resulting distortion of market shares also has legal ramifications. Antitrust cases, in particular, may have outcomes that are influenced by changes in regulatory structure. Our model has demonstrated that a uniform subsidy, in all but the most restrictive cases, perturbs the market share of each firm in the industry. Thus, in a period coinciding with industry taxation or subsidization, the use of concentration indices for policy analysis can significantly alter the outcome of antitrust cases. The effect of taxation on legally defined regulatory limits, such as those outlined by national (and international) antitrust legislation, may, in fact, be an endogenous outcome of the policy decision. 


\section{AUTHORS' NOTE:}

The authors wish to acknowledge valuable comments by Tore Ellingsen, Karl Jungenfelt, Jeff

Perloff, and two anonymous referees. Financial support from the Institute for Fiscal Policy

Research is acknowledged by the second author.

\section{NOTES}

1. Besley's optimal policy also includes a fixed fee for entering the market to prevent excessive duplication of fixed costs. In this article, the number of firms is exogenous.

2. The conjectural variation model is not to be understood as a dynamic model but merely as a way to quickly analyze different degrees of oligopolistic competition in a unified model. The conjectural variation model has been investigated extensively by Seade (1980a, 1980b), Dixit (1986), and Stero (1987).

3. The analysis applies equally well for the case of a uniform production $\operatorname{tax}(\mathrm{t}<0)$.

4. Note that $\Delta=-1$ does not correspond with a Bertrand equilibrium when firms differ in cost efficiency, whence our comparison cannot include that case (see Shapiro 1989, 354). Therefore, the lowest admitted value of $\Delta$ in our analysis is slightly greater than -1 .

5. The arguments for the demand and cost functions are, from this point onward, suppressed.

6. Expression (5) is a common stability condition in the literature on oligopoly (see Hahn 1962; Seade 1980b; Dixit 1986).

7. We wish to thank an anonymous referee for suggesting this line of reasoning. 
8. Similar intuition is provided by Dierickx, Matutes, and Neven (1988).

9. Note that the implications are exactly reversed with production taxes; that is, a tax is less welfare decreasing in the asymmetric case because the high-cost firm is decreasing its production by at least as much as the low-cost firm.

10. In general, it is possible to infer the cost structure of firms based on relative market shares in the industry. Many studies have adopted essentially the inverse approach by calculating market shares based on relative costs. See, for example, Seade (1985); Dierickx, Matutes, and Neven (1988); Shapiro (1989); and Kimmel (1992). 


\section{REFERENCES}

Besley, T. J. 1989. Commodity taxation and imperfect competition: A note on the effects of entry. Journal of Public Economics 40(3):359-67.

Dierickx, I., C. Matutes, and D. Neven. 1988. Indirect taxation and Cournot equilibrium. International Journal of Industrial Organization 6(3):385-99.

Dixit, A. K. 1986. Comparative statics for oligopoly. International Economic Review 27(1): 10722.

Hahn, F. H. 1962. The stability of the Cournot oligopoly solution. Review of Economic Studies 34(3):329-31.

Katz, M. L., and H. S. Rosen. 1985. Tax analysis in an oligopoly model. Public Finance Quarterly 13(1):9-20.

Kimmel, S. 1992. Effects of cost changes on oligopolists' profits. Journal of Industrial Economics 40(4):441-49.

Seade, J. 1980a. On the effects of entry. Econometrica 48(2):479-89.

----. 1980b. The stability of Cournot revisited. Journal of Economic Theory 23(1):15-27.

----- 1985. Profitable cost increases and the shifting of taxation. Economic Research Paper \#260. Coventry, UK: University of Warwick. 
Shapiro, C. 1989. Theories of oligopoly behavior. In Handbook of industrial organization, Vol. 1, edited by R. Schmalensee and R. Willig, 330-414. Amsterdam: North-Holland.

Stern, N. H. 1987. The effects of taxation, price control and government contracts in oligopoly and monopolistic competition. Journal of Public Economics 32(2): 133-58. 
Stephen F. Hamilton is an assistant professor of agricultural economics at Kansas State University. His research interests center on market structure and tax policy.

Rickard Sandin is a research associate in economics at the Stockholm School of Economics. His research interests are in the field of industrial organization. 